\title{
Assessment of facial Golden Proportions in Chinese Adults in Hunan Province
}

\author{
Dr Neesha Shrestha,' Dr Abhilasha khanal,2 Dr Xiao Li Wei3 \\ 'Orthodontist, ${ }^{2}$ Asst Professor, Orthodontic Unit, National Academy of Medical Sciences-Bir Hospital, Kathmandu, Nepal \\ ${ }^{3}$ Assoc Prof, Dept of Orthodontics, Second Xiangya Hospital, Central South University, Hunan, China \\ Correspondence: Dr Neesha Shrestha; Email: drneestha.stha@gmail.com
}

\section{ABSTRACT}

Introduction: The interest of facial esthetics is growing in orthodontics. Golden proportion has been intriguing in the field of esthetics. There is a need of evaluation of facial golden proportions in various population groups.

Objective: To evaluate the relationship between facial parameters and golden proportion among patients for better treatment planning.

Materials \& Method: Cross-sectional study design was used. Out of 356 pre-treatment frontal photographs, skeletal and dental Class I ( $n=186$ ) were differentiated on the basis of $0.7^{\circ} \leq \mathrm{ANB} \leq 4.7^{\circ}$ and molar relationship. Then samples were stratified according to research criteria (Class I=159). After standardization of photographs, printing was done. The landmarks were plotted on photographic prints and parameters were measured manually. Analysis was done using SPSS version 20.0.

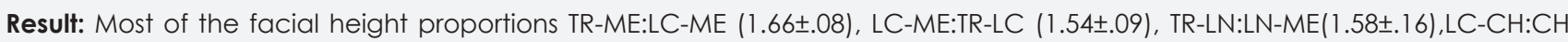
$\mathrm{ME}(1.57 \pm .16)$ in frontal photographs of Class I were more close to the golden proportion. However, facial width proportions showed deviation from the golden proportion.

Conclusion: The vertical proportions in the patients showed closer to the golden proportion compared to the width proportions, indicating more soft tissue balance in vertical height.

Key-words: Class I malocclusion, facial esthetics, golden proportion, soft tissue analysis

\section{INTRODUCTION}

Facial attractiveness has been a desirable physical attribute in societies from ancient time. The contemporary society places significant emphasis on physical appearance especially facial attractiveness, which is strongly related to social acceptance, psychological well-being, and the self-esteem of an individual. ${ }^{1-5}$ So innumerable researches and experiments have been performed with the purpose of understanding esthetics in better aspect, based on every possible available platform, which will ultimately help us to improve and achieve the most acceptable esthetic values. ${ }^{6-10}$ The most famous of these are based on the Golden Proportions. ${ }^{9,11-13}$

Golden Proportion: It is a unique proportion of a line $A B$ into two parts in following way:

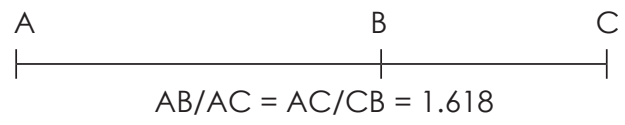

The Greek mathematician Euclid first mentioned the golden proportion in $4^{\text {th }}$ century in his book 'Elements'. However, the ancient Egyptians might have known about the golden proportion earlier, since the proportion found in the large pyramids of Egypt from third century. The famous mathematician Fibonacci from $12^{\text {th }}$ century also defined golden proportion as phi $(\phi)$, which was found to be $1.618 .^{12}$

The subject of esthetics is also obligatory to orthodontists since majority of the patients seek orthodontic treatment with the primary objective of improving their existing facial form. Wahl also quoted" Now it appears that facial esthetics is again in the forefront as we realize why patients come to us in the first place. ${ }^{14}$

Many researches in orthodontics have been done to elaborate facial esthetics. ${ }^{15-17}$ Golden proportion is one of the most used measures for facial esthetics in the literature. ${ }^{13,18-20}$ Ricketts $^{6,21}$ was one of the orthodontists who applied golden proportion for the assessment of facial hard and soft tissues. Proffit ${ }^{22}$ also mentioned that the distance from supra orbital ridges to the base of the 
nose should be equal and furthermore mouth should be about one third distance from base of the nose to the chin. Similarly, more recent articles also discussed about angular and linear analyses of soft tissues. ${ }^{23}$

There is not much information in the literature about facial golden proportion in Chinese. Thus, the main objective of the study was to evaluate the relationship between facial parameters and golden proportion in Chinese adult patients for better orthodontic treatment planning. The knowledge of facial proportion can also be used in the field of maxillofacial surgery and plastic surgery.

\section{MATERIALS AND METHOD}

A cross sectional was conducted after approval from ethical clearance committee of Second Xiangya Hospital. The materials used in this study were frontal photographs, which were derived from patients who came to the Department of Orthodontics, Second Xiangya Hospital, Central South University in Hunan province during 2012 to 2014.The consent was taken before starting the study. The inclusion criteria for selection of the samples were: the subjects should be Chinese in origin and native of Hunan province, young adults of the age range 17-35 years. The subjects were excluded from the study if the subjects had congenital cranio-facial defect, history of dental and facial trauma, and history of previous orthodontic treatment or cosmetic surgery.

Pre-treatment digital lateral cephalograms of the selected patients were retrieved from the computer database. The same experienced radiologist, using the standard radiographic technique, took all the lateral cephalograms keeping the head in natural head position with the help of the cephalostat. The cephalograms with minimal artifacts, no distortions were only included in the study. According to the selection criteria, 356 patients were included in the study. The patients were differentiated into skeletal Class I, Class II and Class III by using computerized cephalometric tracing and analysis software (Planmeca Romexis®-3.2.0) (Table1). All patients were also differentiated into Class I, Class II and Class III according to Angle's classification.

Among 356 patients, frontal photographs of the patients with skeletal and dental Class I were included in the study. The patients wearing glasses were excluded to avoid the

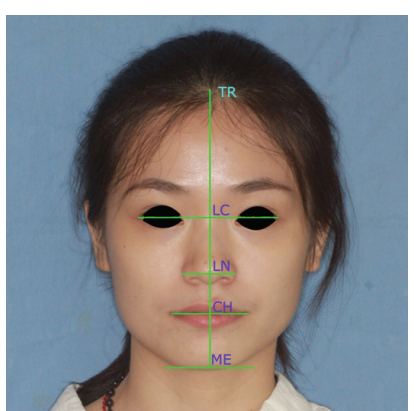

Figure 1: Facial height parameters

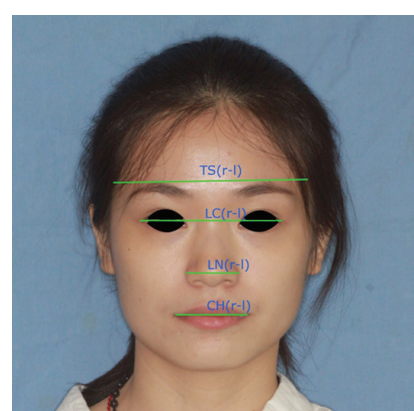

Figure 2: Facial width parameters interference identifying the landmarks. All photographs were taken using DSLR camera [Canon EOS 500D] while the subjects in relaxed position. The distance between subject and background was $0.8 \mathrm{~m}$ and distance between subject and camera was $1.6 \mathrm{~m}$.

All selected photographs $(n=159)$ were printed in A4 size paper. All the parameters were plotted manually and following landmarks were used in printed photographs (Figure 1,2).

Landmarks used:

1. Trichion (TR): The point at the top of the forehead at the junction (hairline) of the face and skull fascia

2. TS: The width of the head at the temporal soft tissue above the ears at the level of the supraorbital ridges (eyebrow)

3. LC: The point at the lateral canthus of the eyes

4. $L N$ : The point at the lateral rim of the nose

5. Sn:Subnasale

6. Cheilion $(\mathrm{CH})$ : The point at the corner of the mouth;

7. ME: Soft tissue menton

Facial heights measured on the frontal photographs:
1. TR-ME,
2. LC-ME,
3. TR-LN,
4. TR-LC,
5. LNME,
6. $\mathrm{LC}-\mathrm{CH}$,
7. CH-ME,
8. LC-LN,
9. $\mathrm{LN}-\mathrm{CH}$

Facial widths measured on the frontal photograph:
10. TS-TS,
11. LC-LC,
12. LN-LN,

13. $\mathrm{CH}-\mathrm{CH}$

Table 1: Distribution of Samples

\begin{tabular}{|l|c|c|c|c|}
\hline \multicolumn{1}{|c|}{ Category } & Class I & Class II & Class III & Total \\
\hline ANB value & $0.7^{\circ} \leq \mathrm{ANB} \leq 4.7^{\circ}$ & $\mathrm{ANB}>4.7^{\circ}$ & $\mathrm{ANB}<0.7^{\circ}$ & \multirow{2}{*}{356} \\
\hline Number & 186 & 107 & 63 & \\
\hline
\end{tabular}


The facial balance in height and width were studied from the parameters as follows:

For proportion of total face height, the components used :

- $\quad$ TR-ME:TR-LC

- TR-ME: LN-ME

- TR-ME:LC-CH

For proportions of face height, the components studied:

- $\quad$ TR-ME:LC-ME

- $\quad$ LC-ME:TR-LC

- TR-LN: LN-ME

- LN-ME:LC-LN

- $\quad \mathrm{LC}-\mathrm{CH}: \mathrm{CH}-\mathrm{ME}$

- $\quad \mathrm{CH}-\mathrm{ME}: \mathrm{LN}-\mathrm{CH}$

- LC-LN: LN-CH
The proportions of face width components measured:

- $\quad \mathrm{CH}(\mathrm{r}-\mathrm{I}): \mathrm{LN}(\mathrm{r}-\mathrm{I})$

- $\quad \mathrm{LC}(\mathrm{r}-\mathrm{-l}): \mathrm{CH}(\mathrm{r}-\mathrm{I})$

- $\quad \mathrm{TS}(\mathrm{r}-\mathrm{I}): \mathrm{LC}(\mathrm{r}-\mathrm{I})$

Mean measurements were converted to percentages, assuming that the golden proportion was $100 \%$.

\section{RESULT}

The data were collected from stratified sample of 159 Class I subjects. All data were analyzed using SPSS 20.0. Data were normally distributed with skewness, kurtosis and Shapiro-Wilk test. Descriptive statistics were computed for all variables in terms of means and standard deviation. Table 2 shows mean and standard deviation for total facial heights and widths proportions. TR-ME:LC-ME (1.6603) was the closest to golden proportion.TR-LN:LNME，LC-ME:TR-LC，LC-CH:CH-ME; 98.03\%,95.75\%，97.19\% respectively were also close to golden proportion. Facial widths showed deviation from golden proportion.

Table 2: Descriptive Statistics for facial height and width proportions

\begin{tabular}{|l|c|c|c|}
\hline \multicolumn{1}{|c|}{ Proportion } & Mean & Std. Deviation & Percentage conversion assuming golden proportion as $100 \%$ \\
\hline TR-ME:TR-LC & 2.4474 & 0.18123 & 151.26 \\
\hline TR-ME:LN-ME & 2.5966 & 0.17617 & 160.48 \\
\hline TR-ME:LC-CH & 2.7857 & 0.17038 & 172.17 \\
\hline TR-ME:LC-ME & 1.6603 & 0.08030 & 102.61 \\
\hline LC-ME:TR-LC & 1.5492 & 0.09900 & 95.75 \\
\hline TR-LN:LNME & 1.5861 & 0.16083 & 98.03 \\
\hline LN-ME:LC-LN & 2.0080 & 0.29275 & 124.10 \\
\hline LC-CH:CH-ME & 1.5726 & 0.16149 & 97.19 \\
\hline CH-ME:LN-CH & 1.4374 & 0.13943 & 88.84 \\
\hline LC-LN:LN-CH & 1.2239 & 0.19263 & 75.64 \\
\hline CHr-I:LNr-I & 1.2974 & 0.17865 & 80.19 \\
\hline LCr-I:CHr-I & 1.9839 & 0.27529 & 122.61 \\
\hline TSr-I:LCr-I & 1.3652 & 0.09243 & 84.38 \\
\hline
\end{tabular}

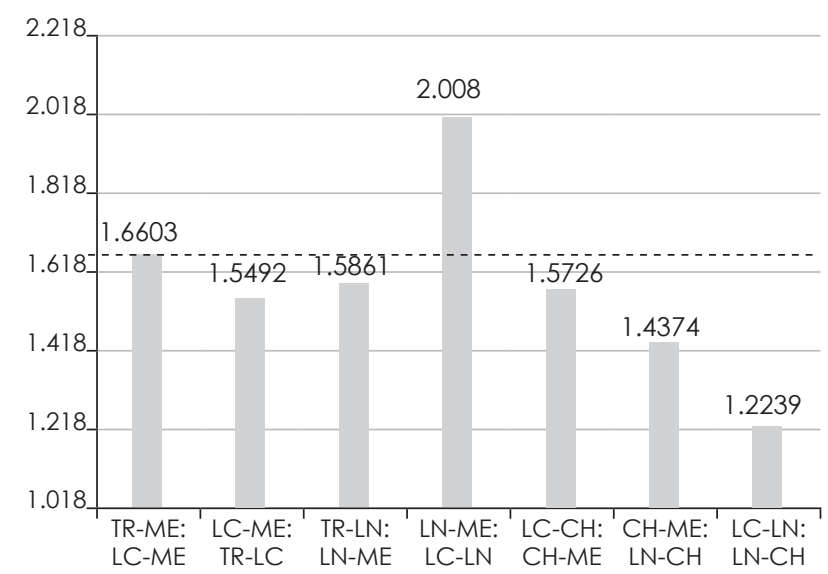

Class 1

Figure 3: Facial height proportions

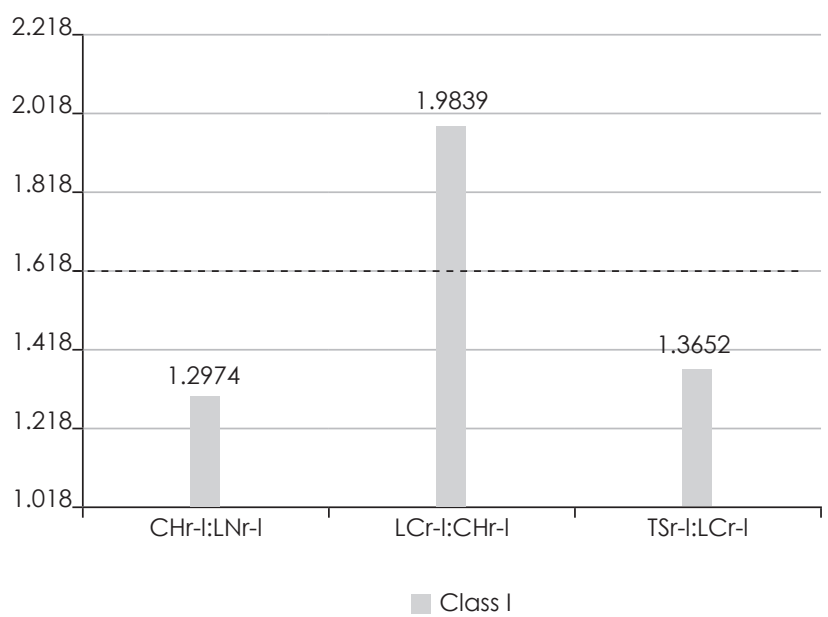

Figure 4: Facial width proportions 


\section{DISCUSSION}

Facial esthetics is always a prime concern in human civilization. Similarly, the golden proportion has been fascinating from the time of ancient Greek history. Rickets6 found that several proportions in face were in harmony with golden proportion and suggested that esthetics was not only the matter of subjective perception. In fact, it can be defined scientifically with the golden proportion. Ithas become standards for esthetics especially facial esthetics regardless of gender, age, race, etc. Fan et a/10 studied the relationship between facial attractiveness and facial proportions by creating average features of facial images from famous ladies of China, Japan and Korea with the help of computer software. They pointed out various proportions that were close to the golden proportion.

In this study, the proportions TR-ME:LC-ME, LC-ME:TR-LC, TR-LN:LN-ME, LC-CH:CH-ME, in Class I were closer to the golden proportion. The proportions LC-LN:LN-ME, LN-CH: $\mathrm{CH}-\mathrm{ME}$ and $\mathrm{LC}-\mathrm{LN}: \mathrm{LN}-\mathrm{CH}$ were deviated from golden proportion. Similarly, Kawakami et a ${ }^{24}$ found the values of $\mathrm{AL}$ (equivalent to $\mathrm{LN}$ in this study) $\mathrm{CH}: \mathrm{CH}-\mathrm{ME}$, and $\mathrm{AL}(\mathrm{LN})$ $\mathrm{CH}: \mathrm{LCAL}(\mathrm{LN})$ deviated from the golden proportion. The deviations indicated a shorter $\mathrm{AL}(\mathrm{LN})-\mathrm{CH}$ and a longer
CH-ME than those of white people. However, Kawakami et al found $\mathrm{CH}-\mathrm{ME}$ :LC-CH deviation from golden proportion while this study showed closed to the proportion.

Similarly Mizumoto et $a^{25}$ found five of the seven measurements of face height [TR-ME:LC-ME; LN-ME:TR-LN; TR-LC:LC-ME; CH-ME:LC-CH; LN-CH:CH-ME] were close to golden proportion, whereas LC-LN:LNME and LN-CH:LC$\mathrm{LN}$ deviated from the golden proportion. Sunilkumar et $\mathrm{a}^{20}$ found four of the parameters of face height were close to golden proportion in Indian subjects. The values of TRLN:LN-ME, LN-ME:LC-LN and LC-LN:LNCH deviated from the golden proportion.

\section{CONCLUSION}

Most of the parameters for facial balance in Chinese population in Hunan showed proportionality when compared with the golden proportion. However, some parameters for the lower facial height and width deviated from the golden proportion. The values obtained should be taken into consideration in orthodontic treatment planning or orthognathic surgery.

\section{OJN}

\section{REFERENCES}

1. Laurentini A, Bottino A. Computer analysis of face beauty: A survey. Computer Vision and Image Understanding. 2014;125(0):184-99.

2. Chiu RK, Babcock RD. The relative importance of facial attractiveness and gender in Hong Kong selection decisions. Int J Human Resource Management. 2002;13(1):141-55.

3. Adamson PA, Doud Galli SK. Modern concepts of beauty. Plastic surgical nursing.J Am Soc Plastic Reconstructive Surgical Nurses. $2009 ; 29(1): 5-9$

4. Buhlmann U, Teachman BA, Naumann E, Fehlinger T, Rief W. The meaning of beauty: Implicit and explicit self-esteem and attractiveness beliefs in body dysmorphic disorder. J Anxiety Disorders. 2009;23(5):694-702.

5. Rankin M, Borah GL, Perry AW, Wey PD. Quality-of-life outcomes after cosmetic surgery. Plastic \& Reconstructive Surg. 1998;102(6):2139-45.

6. Ricketts RM. The biologic significance of the divine proportion and Fibonacci series. AmJ Orthod. 1982;81 (5):351-70.

7. Villegas C, Uribe FA, Nanda R. Esthetics and New Approaches to Orthognathic Surgery Chapter-21. Esthetics and Biomechanics in Orthodontics (2nd Ed.). St. Louis: W.B. Saunders; 2015. p. 423-41.

8. Mani V. Face and beauty in the fourth dimension: Traverse of face and beauty through time. Int J Oral Maxillofac Surg. $2007 ; 36$ (1 1):1024.

9. Gunes H, Piccardi M. Assessing facial beauty through proportion analysis by image processing and supervised learning. Int J HumanComputer Studies. 2006;64(12):1184-99.

10. Fan J, Chau KP, Wan X, Zhai L, Lau E. Prediction of facial attractiveness from facial proportions. Pattern Recognition. 2012;45(6):2326-34.

11. Al-Marzok MI, Majeed KR, Ibrahim IK. Evaluation of maxillary anterior teeth and their relation to the golden proportion in Malaysian population. BMC Oral Health. 2013;13:9

12. Kiekens RMA, Kuijpers-Jagtman AM, van 't Hof MA, van ' + Hof BE, Maltha JC. Putative golden proportions as predictors of facial esthetics in adolescents. Am J Orthod Dentofac Orthop. 2008;134(4):480-3.

13. Rossetti A, De Menezes M, Rosati R, Ferrario VF, Sforza C. The role of the golden proportion in the evaluation of facial esthetics. Angle Orthod. 2013;83(5):801-8.

14. Wahl N. Orthodontics in 3 millennia. Chapter 7: Facial analysis before the advent of the cephalometer. Am J Orthod Dentofac Orthop. 2006;129(2):293-8.

15. Chong HT, Thea KW, Descallar J, Chen Y, Dalci O, Wong R. Comparison of White and Chinese perception of esthetic Chinese lip position. Angle Orthod. 2014;84(2):246-53.

16. Jacobson A. Facial geometry: Graphic facial analysis for forensic artists, Robert M. George. Charles C. Thomas (2007). Am J Orthod Dentofac Orthop. 2009;135(1):137. 
17. Arnett GW, Bergman RT. Facial keys to orthodontic diagnosis and treatment planning--Part II. Am J Orthod Dentofac Orthop. 1993;103(5):395-411.

18. Levin El. Dental esthetics and the golden proportion. J Prosth Dent. 1978;40(3):244-52.

19. Hasanreisoglu U, Berksun S, Aras K, Arslan I. An analysis of maxillary anterior teeth: Facial and dental proportions. J Prosth Dent. 2005;94(6):5308.

20. Sunilkumar LN, Jadhav KS, Nazirkar G, Singh S, Nagmode PS, Ali FM. Assessment of Facial Golden Proportions among North Maharashtrian Population. J Int Oral Health. 2013:5(3):48-54.

21. Ricketts RM. The golden divider. J Clin Orthod. 1981;15(11):752-9.

22. Profitt WR FH. Contemporary Othodontics.3rd Ed.StLouis:Mosby. 1997:157-63.

23. Fernandez-Riveiro P, Smyth-Chamosa E, Suarez-Quintanilla D, Suarez-Cunqueiro M. Angular photogrammetric analysis of the soft tissue facial profile. Euro JOrthod. 2003;25(4):393-9.

24. Kawakami S, Tsukada S, Hayashi H, Takada Y, Koubayashi S. Golden proportion for maxillofacial surgery in Orientals. AnnPlast Surg. 1989:23(5):417-25.

25. Mizumoto Y, Deguchi T Sr, Fong KWC. Assessment of facial golden proportions among young Japanese women. Am J Orthod Dentofac Orthop. 2009;136(2):168-74. 